\title{
Exploiting potency of negative pressure in wound dressing using limited access dressing and suction-assisted dressing
}

\author{
Pramod Kumar \\ Department of Plastic Surgery and Burns, Kasturba Medical College, Manipal University, Karnataka, Manipal, India \\ Address for correspondence: Dr. Pramod Kumar, Department of Plastic Surgery and Burns, Kasturba Medical College, \\ Manipal University, Karnataka, Manipal - 576 104, India. E-mail: kumar.drpramod@hotmail.com
}

\section{ABSTRACT}

Role of negative pressure dressing and moist wound healing are well established in the treatment of both acute and chronic wounds with certain advantages and disadvantages in both the techniques. Both these techniques prevents wound colonization, but the negative pressure dressing method has proved to have a greater potency to remove secretions, prevent wound invasion and eradication established infection. In both these techniques there is no accessibility to wound environment. Limited access dressing (LAD) is a moist wound dressing with negative pressure. It provides limited access to the wound through two small ports for both dressers and pathogens. The LAD design has notable advantages like wound isolation that reduces chance of wound colonization and safe disposal of infected materials (important factor to reduce hospital-acquired infections), while avoiding some major disadvantages such as opacity of dressing materials, inaccessible offensive smelling wound environment, and relatively high treatment costs. In LAD a definite intermittent negative pressure regimen is followed. The intermittent negative pressure (cycle of 30 minutes suction and $3 \frac{1}{2}$ hours rest) is effective. Overall, the LAD is a safe and effective alternative to conventional dressing methods. LAD is an excellent research tool for wound healing as frequent/continuous record of wound healing is possible without disturbing the wound healing process. LAD is an effective dressing for limb salvage in cases of acute and chronic complex wounds. Leech effect prevents wound related systematic response syndrome and sepsis. Suction-assisted dressing (SAD) is a combination of semiocclusive dressing with negative pressure. It works by removal of fluids by intermittent (like LAD) negative pressure and preventing bacterial invasion. SAD is especially advantageous where soakage is less, there is no dead tissue covering the wound (e.g., following skin grafting), superficial skin wounds (e.g., donor area) and also where LAD is technically difficult to apply over circumferential trunk and neck dressings under anesthesia.

\section{KEY WORDS}

Limited access dressing; negative pressure wound therapy; suction-assisted dressing

\section{INTRODUCTION}

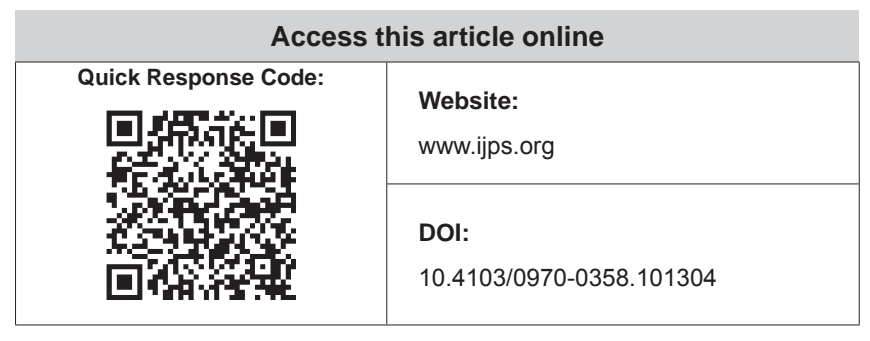

Indian Journal of Plastic Surgery May-August 2012 Vol 45 Issue 2 egative pressure wound dressing and moist wound dressings have proven to be very effective in acute and chronic wound management, and in many instances it has become the standard of care. However, different devices (VAC Therapy, Versatile 1) claim to deliver continuous negative pressure wound 
therapy (NPWT). They do not have the same efficacy and indications..$^{[1,2]}$

The major disadvantages in their wide spread acceptance is its cost, requirement of special suction machine, lack of visibility of wound bed during treatment, anaerobic infection, foul smell and difficulty in manipulation of wound environment.

Moist wound dressings retain moisture, heat, body fluids, and medication. It maintains the moist and warm wound environment suitable for growth of the granulation tissue, controls wound infection, increases of epithelialization and reduces pain. However, there is concern that a moist environment may lead to bacterial proliferation and wound infection. ${ }^{[3-5]}$ Moist wound healing achieved by occlusive hydrocolloid produces offensive-smelling exudates and has raised some doubt about its effect on bacterial flora, specifically anaerobes. ${ }^{[6,7]}$ The bad odour that is produced has been explained as a result of either gelatin breakdown in the colloid gel ${ }^{[7]}$ or anaerobic infection. ${ }^{[7-9]}$ An occlusive dressing that traps moisture on intact skin can produce an explosive proliferation of bacteria. ${ }^{[10,11]}$

Limited Access Dressing (LAD) ${ }^{[12,13]}$ is combines a moist wound dressing with negative pressure. LAD reduces or eliminates the disadvantages of both negative pressure and moist dressings. It is cost effective and uses of low intermittent negative pressure that can be delivered even by ordinary suction machine.

Majority of the moist wound dressings absorb exudates, produces an absorption gradient that removes (to some extent) the toxic components of the wound exudates. ${ }^{[14]}$ Unlike moist healing materials, the capacity of negative pressure to remove fluid is unlimited and can be used to treat wound with any amount of soakage. Semiocclusive (gauze and bandage) dressings like occlusive (hydrocolloids) dressing occasionally due to moist environment can cause over hydration of wound and maceration. To reduce this problem associated with moist environment of bandage technique, author has devised a suction assisted dressing (SAD) where semiocclusive dressing is combined with negative pressure. ${ }^{[15]}$ SAD is easy to apply especially under anesthesia.

\section{Limited access dressing: The concept and applications}

The Limited access dressing (LAD) is a combination of intermittent negative pressure (for 30 minutes) and a moist wound dressing (for $3 \frac{1}{2}$ hours without negative pressure) (a total of 3 hours negative pressure dressing and 21 hours of moist dressing in a 24-hour period). ${ }^{[2,3]}$ Negative pressure (intermittent) is applied through tubing connected to a suction machine that is then placed under a polythene wound cover. LAD retains all the advantages of moist wound healing and negative pressure dressings and avoids/ reduces all of their disadvantages by manipulating the wound environment through tubes.

\section{How much and how frequent intra-LAD negative pressure is effective to prevent bacterial invasion and absorption of chemicals (toxins)?}

There is a general belief among most physiologists that true interstitial fluid pressure in loose subcutaneous tissue is slightly less than atmospheric pressure (average value of this pressure is negative in relation to atmospheric pressure and is approximately- $3 \mathrm{mmHg}){ }^{[16]}$

When the skin cover is absent in wounds, the pressure will rise to $0 \mathrm{mmHg}$ (i.e., equal to atmospheric pressure). These increases in interstitial tissue pressure from - $3 \mathrm{mmHg}$ to 0 $\mathrm{mmHg}$ will also cause the lymph flow to increase 20 -fold ${ }^{[16]}$ and the reabsorption of fluid to increase through capillaries. Hence, the chances bacterial invasion and absorption of chemicals (toxins) through venules and lymphatics increases when edema increases the interstitial tissue pressure or produces an open wound that is not sutured.

If the interstitial tissue pressure is slightly more negative than $-6 \mathrm{mmHg}$, the lymph flow is slight ${ }^{[16]}$ and consequently, the absorption of interstitial fluid will be negligible. As a result, the risk of sepsis due to bacterial invasion and the risk of systemic inflammation syndrome (SIRS) due to absorption of proinflammatory cytokines will reduce considerably at $-6 \mathrm{mmHg}$ [Table 1].

Surgeons generally believe that after wounding the wound remains contaminated for 6-8 hours, after which bacterial invasion occurs. If negative pressure (more than $-30 \mathrm{mmHg}$ ) is applied every $3 \frac{1}{2}$ hours for 30 minutes chances of invasive wound sepsis and SIRS will be reduced considerably-the author determined this schedule by a trial and error method and through daily observation of changes in wound granulation appearance after applying the LAD in more than 1000 cases while generating a maximum -30 $\mathrm{mmHg}$ negative pressure through the suction machine. This level of pressure $(-30 \mathrm{mmHg})$ not only appears to be safe for most of the tissues, but also produces a desirable negative pressure effect even if 
slight leakage occurs. Clinical experience reveals that the pain and discomfort experienced by the patient during suction is usually directly proportional to the negative pressure applied. Even more than $-30 \mathrm{mmHg}$ negative pressure applied over the wound will be effective and higher negative pressure may be applied, provided the pain produced is tolerable and there is no abnormal bleeding. Hence, the minimum negative pressure $(-30 \mathrm{mmHg}$ on target tissue) required is to be stressed by the surgeon, negative pressure more than that should be the concern of the patient. Therefore, the author has changed his earlier concept of application of $30 \mathrm{mmHg}$ negative pressure to the pressure between $30 \mathrm{mmHg}$ and maximum tolerable limit. Literature search reveals that $125 \mathrm{mmHg}^{1}$ negative pressure has been safely used.

LAD is very effective in eradicating both Gram-positive $(100 \%)$ and Gram-negative bacteria (98.74-100\%). In postLAD period by $7^{\text {th }}$ day surface swab shows new growth of gram negative bacteria in $57.14 \%(12 / 21)$ cases..$^{[1]}$ This may be explained by contamination during LAD wash/through leak site. LAD is effective to prevent wound invasion by new contaminants.

Also, LAD is effective in eradication of resistant bacterial infections. We studied the efficacy of LAD in eradication of resistant bacterial infections (2010; unpublished) - Out of 60 patients under study, in 57 (95\%) patients bacterial growth was detected, treatment with LAD for 10 days resulted in no growth in $34 / 57$ (59.6\%) patients, and reduction in the number of organisms in 19/57 (33.33\%) patients. Identification and antibiotic susceptibility was done using CLSI (clinical laboratory standard institute, USA) guidelines. The strains were checked for multi-drug resistant enzyme production using disk approximation method and biofilm formation ability was tested using microtitre well method. Ninety-three ( $n=93)$ pre-LAD isolates were reduced to 26 $(\mathrm{n}=26)$ after 10 days treatment of wounds in LAD [Table 2].

Wound secretion collected inside LAD during rest period has various enzymes (tissue enzymes and enzymes secreted by the bacteria), toxins produced by microorganisms and toxic products due to putrefaction of dead tissue. These are harmful to rapidly dividing cells during angiogenesis (granulation) and epithelialization, and effective negative pressure removes them. In LAD daily progress in wound bed can be monitored through transparent polythene.

\section{CONCEPT OF TARGET TISSUE}

The target tissue covered by the tough necrotic tissue may not be effectively exposed to negative pressure. To get desired effect the target tissue must be exposed to negative pressure surgically (by multiple incisions or excision of tough covering). This concept is utilized effectively by placing drain(s) in deeper tissue, closing the skin and applying LAD. The drains thus placed help the negative suction of the LAD bag to be transmitted to the deeper tissue.

Also, the effective negative pressure applied over the

Table 2: Effect of LAD on bacterial growth

\begin{tabular}{|c|c|}
\hline Pre-LAD isolates & Post-LAD (10 ${ }^{\text {th }}$ Day $)$ isolates \\
\hline $\begin{array}{l}\text { Total number of isolates } \\
\text { (n) grown }=93\end{array}$ & Total number of isolates $(n)$ grown $=26$ \\
\hline $\begin{array}{l}{\left[\text { Total } \mathrm{MDR}^{+} \text {isolates }=52 ;\right.} \\
\text { Other isolates }=41]\end{array}$ & $\begin{array}{l}{\left[\text { Total } \mathrm{MDR}^{+} \text {isolates }=15 ; \text { Other }\right.} \\
\text { isolates }=11]\end{array}$ \\
\hline $\begin{array}{l}\text { Biofilm } \\
\text { producers }=35(37.6 \%)\end{array}$ & Biofilm producers $=2(7.6 \%)$, \\
\hline $\mathrm{ESBLs}^{\dagger}=24(25.4 \%)$ & $\mathrm{ESBLs}=6(23.07 \%)$ \\
\hline $\mathrm{AmpC}^{\dagger}=8(8.6 \%)$ & $\mathrm{AmpC}=4(15.38 \%)$ \\
\hline $\begin{array}{l}\text { MBL producers }=17 \\
(18.2 \%)\end{array}$ & $M B L=5(19.2 \%)$ \\
\hline
\end{tabular}

Table 1: Effect of $-6 \mathrm{mmHg}$ negative pressure on lymph flow, SIRS and sepsis

\begin{tabular}{|c|c|c|c|}
\hline Events & When skin is intact & Open wound & $\begin{array}{l}\text { Effect of applying negative } \\
\text { pressure (-6 } \mathrm{mmHg})(L A D / S A D)\end{array}$ \\
\hline Interstitial tissue pressure & $\begin{array}{l}\text { Subcutaneous tissue pressure } \\
\text { negative }(-3 \mathrm{mmHg}) \text { as } \\
\text { compared to atmospheric } \\
\text { pressure }\end{array}$ & $\begin{array}{l}\text { Subcutaneous tissue } \\
\text { pressure becomes equal } \\
\text { to atmospheric pressure } \\
\text { (Difference }=0 \mathrm{mmHg} \text { ) }\end{array}$ & $\begin{array}{l}\text { Subcutaneous tissue pressure } \\
\text { becomes negative }(-6 \mathrm{mmHg})\end{array}$ \\
\hline Lymph flow & Normal & $\begin{array}{l}\text { Increases to } 20 \text { folds (since } \\
\text { pressure increases from } \\
\text { negative to } 0 \mathrm{mmHg} \text { ) }\end{array}$ & Nil or negligible \\
\hline Absorption of fluid through venules & Normal & Increased & Decreased \\
\hline $\begin{array}{l}\text { Bacterial invasion, Absorption of } \\
\text { chemicals and toxins }\end{array}$ & $\begin{array}{l}\text { Speed of lymphatic spread } \\
\text { depends on lymphatic } \\
\text { drainage }\end{array}$ & Increased & $\begin{array}{l}\text { Leech effect } \\
\text { (SIRS/sepsis reduced) }\end{array}$ \\
\hline
\end{tabular}


target tissue of the wound is less than that measured at the suction machine. The reduction in the negative pressure from machine to the target tissue depends on the length, caliber, kink or partial blockade (by dried secretions) of the tubes, size of the LAD bag, amount of the leak in the system and dead tissue/slough covering the target tissue. To have better idea about the effective pressure, measuring pressure over the wound would be ideal, but it will make the system costlier and procedure more cumbersome. Clinically, we have observed that the negative pressure is effective if application of negative pressure produces folds in $0.15-\mathrm{mm}$ thick LAD plastic, and the folds thus produced is snugly sitting over the wound/skin surface [Figure 1a].

\section{Leech effect of limited access dressing}

The intermittent negative pressure produces a leech effect that is beneficial in the following ways:

1. It prevents bacterial invasion, ${ }^{[16,17]}$ removes proinflammatory cytokines, and bacterial toxins along with the wound secretions.
2. Intermittent negative pressure can possibly retain local, beneficial effects of cytokines (inflammation, fibroplasia) during the rest period.

3. It helps to relieve venous congestion and increases tissue oxygenation.

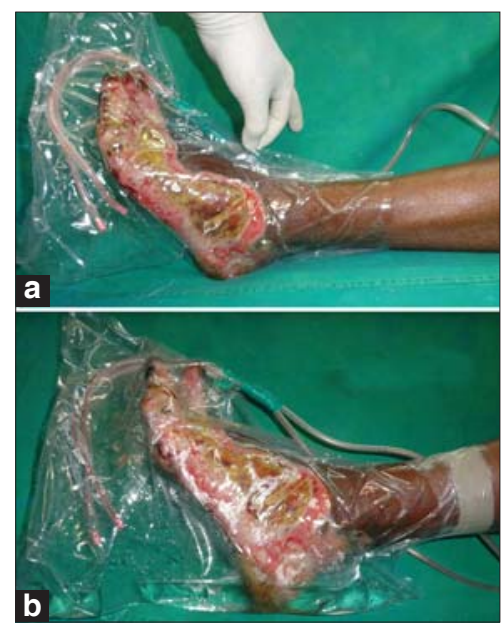

Figure 1: (a) LAD showing fold on application of negative pressure; (b) a recess is incorporated the design of polyethylene LAD bag or tube to hold secretion and reduce the chances of leak

Table 3: Effect of LAD on MODSI MOF and SIRS

\begin{tabular}{lccc}
\hline & Control group $(\boldsymbol{n}=\mathbf{2 7})$ & LAD group $(\boldsymbol{n}=\mathbf{2 7})$ & Significance \\
\hline M: F & $12: 15$ & $14: 13$ & - \\
Mean age & $38.81 \mathrm{yrs} \pm 21.66$ yrs & $30.74 \pm 14.90 \mathrm{yrs}$ & $P$ value 0.036 (significant) \\
Mean TBSA & $35.11 \% \pm 10.87 \%$ & $33.78 \% \pm 17.84 \%$ & $P$ value 0.003 (significant) \\
SIRS & & & $P$ value 0.742 (Not significant) \\
Day 1 & 26 & 23 & $P$ value 0.029 (Significant) \\
Day 5 & 18 & 10 & - \\
Organ dysfunction & 0 & 0 & $P$ value 0.017 (Significant) \\
Day 1 & 12 & 5 & \\
Day 5 & & & \\
\hline
\end{tabular}

Table 4: Odd ratio analysis to find difference in SIRS and Organ dysfunction between control and LAD group

\begin{tabular}{lccc}
\hline Variables & Odd ratio & 95\% Confidence interval & \multicolumn{1}{c}{ P value } \\
\hline SIRS & & & Not significant \\
Day 1 & 4.52 & $(0.471,43.250)$ & $<0.05$ (Significant) \\
Day 5 & 3.4 & $(1.110,10.355)$ & - \\
Organ dysfunction & & - & $<0.5$ (Significant) \\
Day 1 & - & $(1.24,16.962)$ & \\
Day 5 & 4.6 & & \\
\hline
\end{tabular}

Table 5: Table showing classification of LAD leak and its management

\begin{tabular}{lll}
\hline Type of leak & Features & Management \\
\hline Minor leak & Application of negative pressure produces folds snugly sitting & Reseal/ may be ignored \\
& over the wound/ skin surface in 0.15-mm thick LAD plastic & \\
[Figure 1] & $\begin{array}{l}\text { Application of negative pressure produces folds in 0.15-mm } \\
\text { thick LAD plastic but not snugly stick over the wound/ skin } \\
\text { surface }\end{array}$ & Reseal \\
Major leak & $\begin{array}{l}\text { Application of negative pressure does not produce proper } \\
\text { folds in 0.15-mm thick LAD plastic and wound secretion is } \\
\text { not cleared from the LAD bag after the end of suction period } \\
\text { in spite of resealing }\end{array}$ & Change the LAD \\
\hline
\end{tabular}




\section{Clinical usefulness of leech effect}

Our initial experience indicates that use of LAD leads to reduction in incidence of MODS/ MOF and SIRS.

In a preliminary study (August 2005-September 2007 at

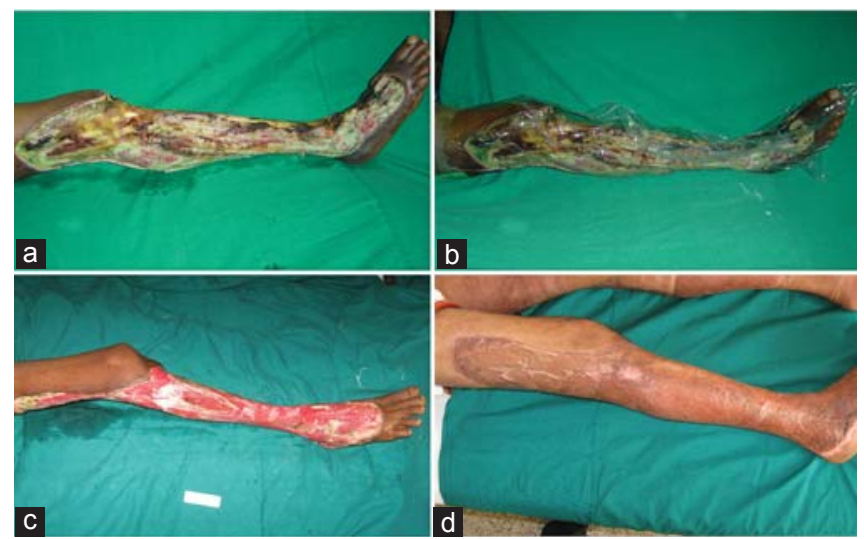

Figure 2: (a) Photograph showing necrotizing fascitis of right lower limb; (b) Wound bed prepared under LAD; (c) Appearance after 2 weeks post-LAD; (d). Appearance after 12 weeks post-skin graft
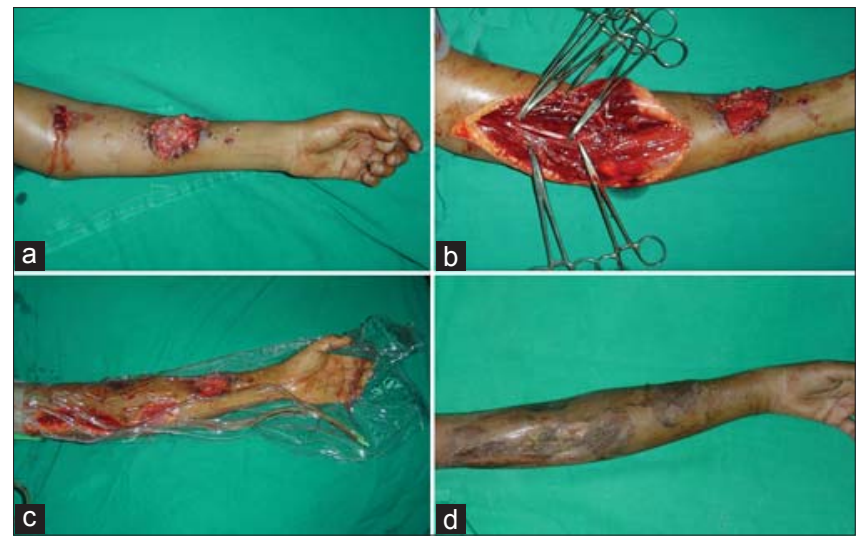

Figure 3: (a) A case of brachial artery injury by sickle; (b) Saphenous vein graft was used to reconstruct the artery in emergency; (c) Reconstructed artery was covered by suturing adjacent muscle over it and wound treated under LAD till healthy granulation appeared; (d) Result after 1 month of injury (Split skin graft was applied over granulation)

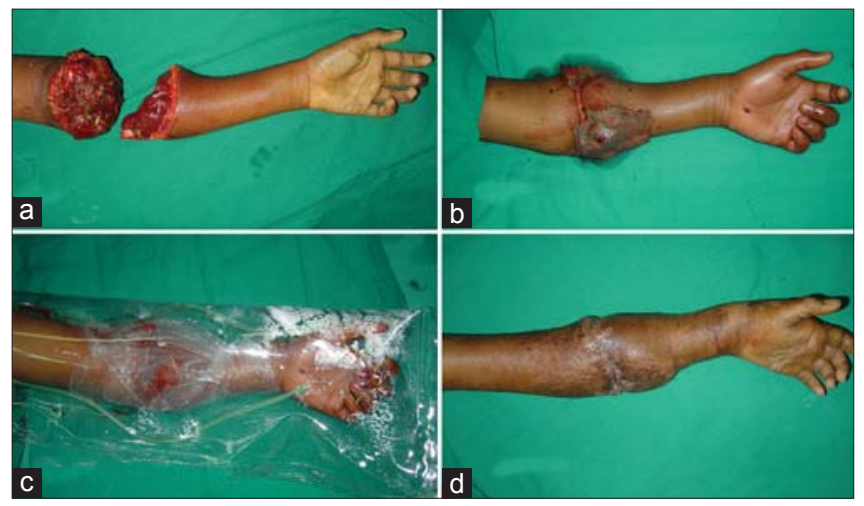

Figure 4: (a) Photograph showing amputation at forearm level; (b) replantation of forearm; (c) Postoperative management of forearm was done under LAD; (d) Photograph after 8 weeks showing successful replantation.
Burns ward Kasturba Medical College, Manipal) to prove leech effect two identical groups of 54 thermal burns (less than 48-hr duration) patients were made: Control group and LAD (intermittent negative pressure) treated group each comprising of 27 extremities burn. There was no statistically significant difference in occurrence of SIRS in both group on Day 1, but on Day 5 the difference was significant [Table 3].

None of the cases in either group had organ dysfunction on day 1 . Two groups had significant difference ( $P$-value.017) in occurrences of organ dysfunction on day 5 [Table 3].

To alleviate the greater risk due to significant difference in mean age and percentage of burn between the two groups [Table 3], odd ratio was analyzed [Table 4]. The difference in SIRS on Day 1 between two groups was not significant, but on Day 5 was significant [Table 4]. The difference in organ dysfunction on Day 5 between two groups was also significant [Table 4].

\section{INDICATIONS OF LAD}

1. To prevent wound colonization (by wound isolation) and wound-related SIRS and infection by negative pressure

2. To treat infection (acute, subacute, chronic wounds including diabetic, osteomyelitis, infection in cases of radiation ulcers [Figure 2 a-d]. Prevention of infection, intermittent compression (reduced stasis) and visibility under LAD appears to improve chances of success after micro vascular surgery though yet to be proved by proper studies [Figures $3 \mathrm{a}-\mathrm{d}$ and 4 a-d]. LAD does not interfere with evaluation of color, capillary refill, turgor, surface temperature, and intensity of arterial/venous Doppler signals. Pinprick through the LAD plastic to evaluate the flap congestion (dark blood) is possible and site of puncture on LAD polythene can be resealed easily

3. To protect tissue (periosteum, perichondrium, paratenon, articular cartilage and synovial membrane in exposed joint), exposed intra-abdominal structures in cases of abdominal wall defect) from desiccation and progressive necrosis following debridement in trauma cases [Figure 5]

4. To facilitate autodebridement [Figure 6]

5. To promote granulation tissue to cover implant, bone, cartilage, tendon [Figures 5-8] 

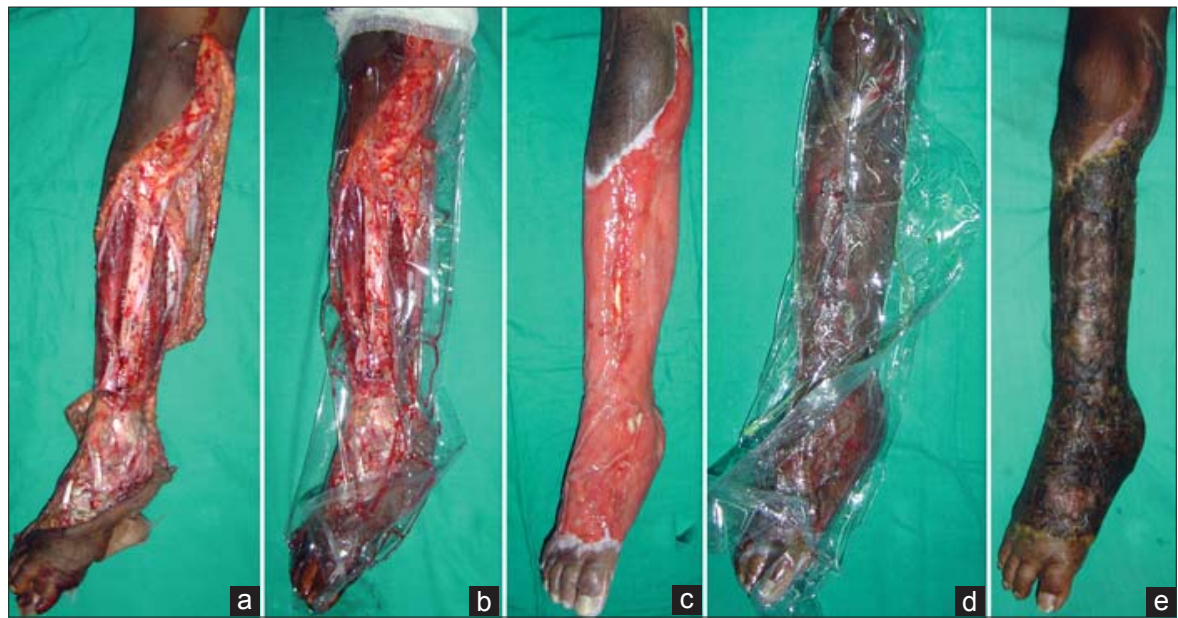

Figure 5: (a) Crush avulsion injury of leg with exposed bone and tendons; (b) Wound prepared with LAD; (c) Appearance of the granulation covering tendons and bones after 52 post-LAD days; (d) Skin grafting under LAD; (e) Appearance after 6 week of skin grafting

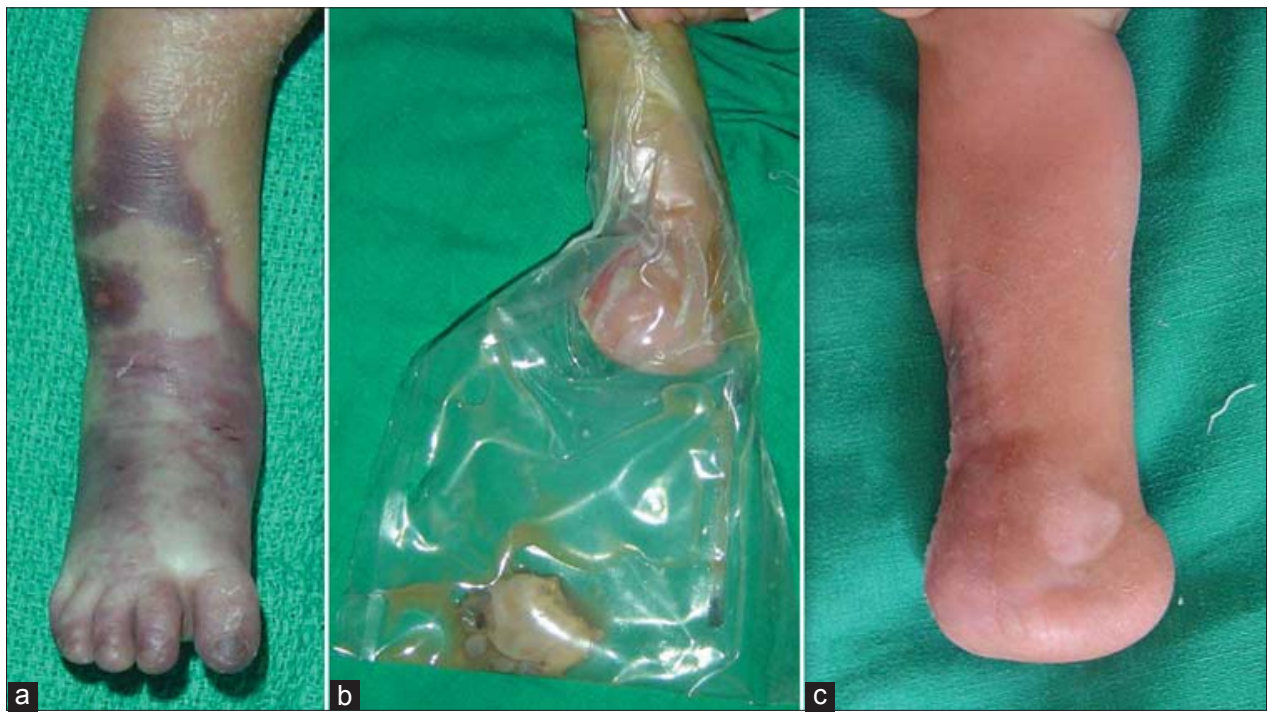

Figure 6: (a) Foot gangrene following intravenous fluid transfusion in a neonate; (b) Intra-LAD auto amputation in 4-weeks duration; (c) Stump wound healed in 7 weeks following management under LAD.

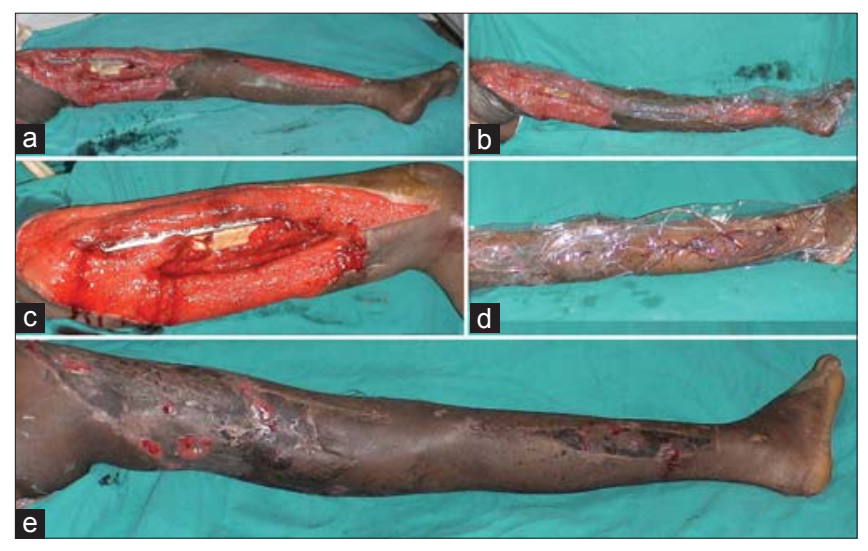

Figure 7: $(a, b)$ Showing exposed stainless steel plate that was used to fix fracture shaft femur; (c) Wounds managed under LAD. Muscles sutured over plate after appearance of healthy granulation tissue; (d) Split skin graft applied over granulating wound under LAD; (e) appearance after 7 weeks

6. To replace daily conventional dressing compound fractures (avoids unnecessary movements as dressing change not required)

7. To improve take of the split skin graft and donor area healing [Figure $5 \mathrm{~d}$ and e]

8. To achieve wound isolation in immune-compromised and high-risk patients (HBsAg and HIV infection)

9. To manage wounds with Maggots ${ }^{[18]}$

10. Miscellaneous indications: Abdominal wall reconstruction [Figure 9] and intra-LAD tissue expansion adjacent to the wound, ${ }^{[12]}$ to achieve faster healing in Ehler Danlos Syndrome. ${ }^{[19]}$ The LAD may be applied after abscess drainage and after 7-10 days (before skin edges retract significantly) secondary suturing over the suction drain may be done to promote faster healing and a better quality scar. Continuous intra-LAD cold saline irrigation may be useful in controlling hyperpyrexia.

Indian Journal of Plastic Surgery May-August 2012 Vol 45 Issue 2 


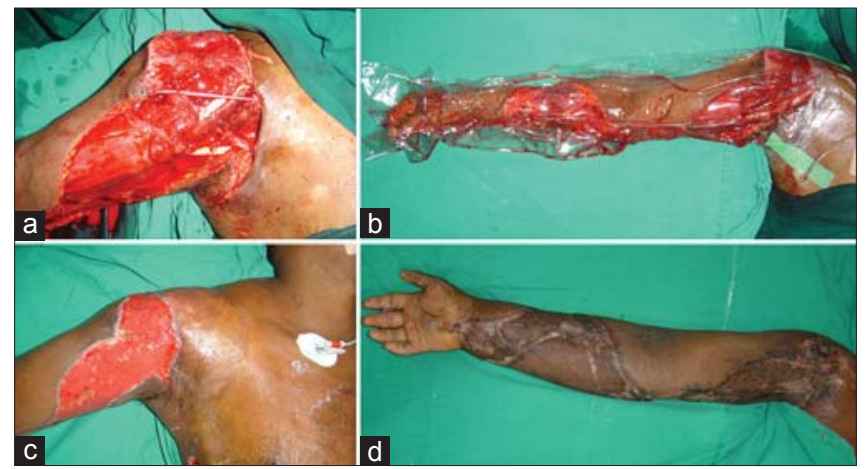

Figure 8: (a) Photograph showing grotex implant that was used to reconstruct brachial artery damaged in road traffic accident and fasciotomy wound; (b) Wounds treated under LAD; (c) Implant covered under healthy granulation tissue in 4 weeks; (d) Result 2 weeks after skin grafting.
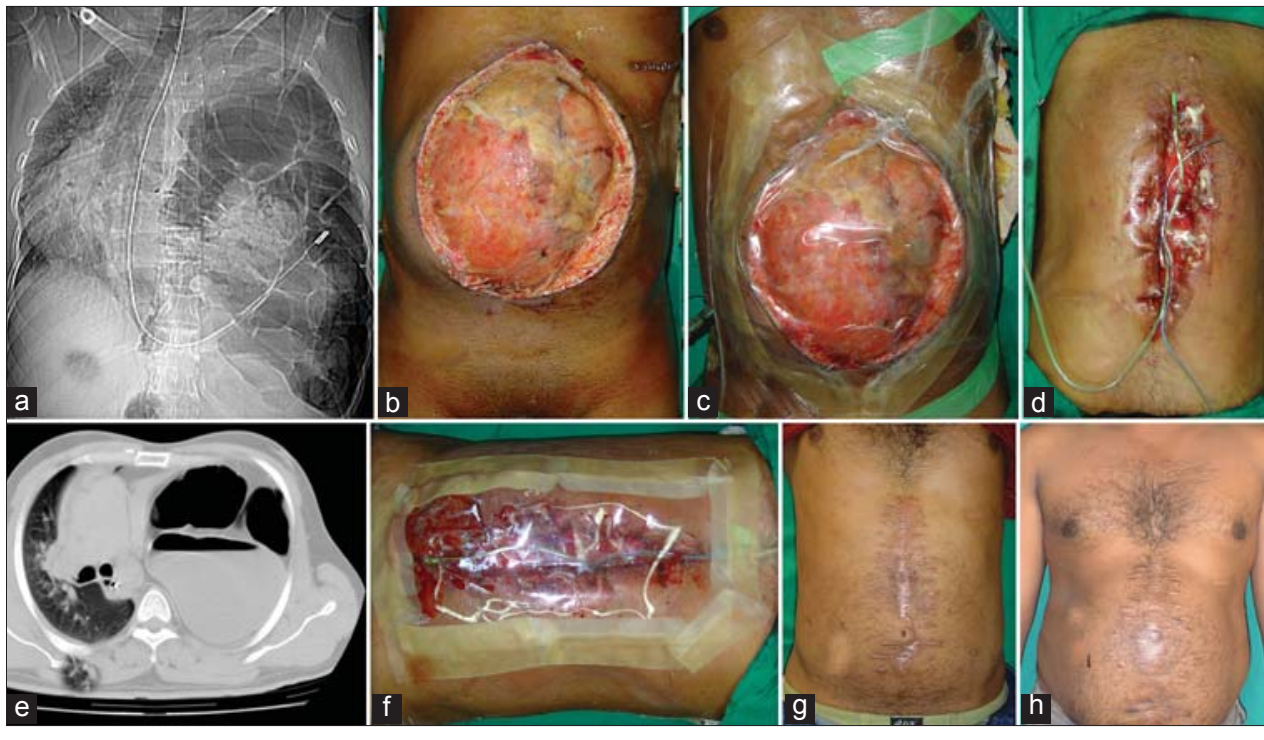

Figure 9: $(a, b) C T$ thorax to showing large diaphragmatic hernia; (c) After reduction and repair of diaphragmatic hernia abdominal wall defect could not be closed and mesh repair without skin cover was done by cardiothoracic surgery; (d-f) LAD was applied after $48 \mathrm{hrs}$ and changed every 7 days or when severe leak occurred. At each dressing change tension sutured was applied for expansion of abdominal wall. Abdominal wall could be closed in 1 month; (g) Appearance after 3 months of closure; (h) Appearance after $1 \frac{1}{2}$ years

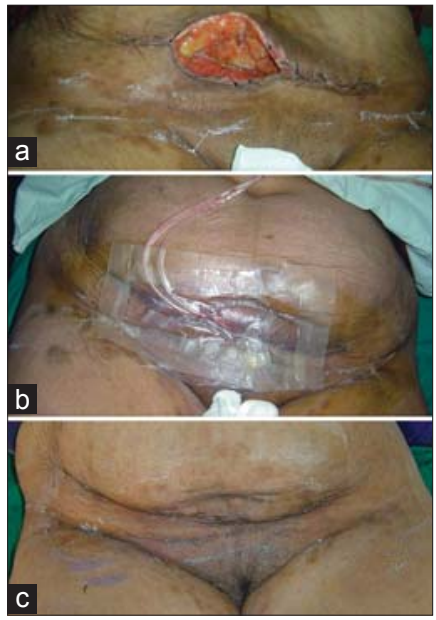

Figure 10: (a) Dehiscence of abdominal wall wound after caesarian section; (b) Wound managed by LAD (intermittent low negative pressure) for 20 days;

(c) Secondary suturing after minor debridement was done to close the wound permanently

LAD may have beneficial effect on wound healing in borderline vascular compromised limb by effective control of infection and provision of moist environment.

We have used LAD in lymphorrhoea, lymphedema with infected wounds and over exposed abdominal fat [Figure 10] following dehiscence after Caesarean section wound successfully.

LAD is an excellent research tool for wound healing as frequent/ continuous record of wound healing is possible without disturbing the wound-healing process. LAD is an effective method of dressing for limb salvage in diabetic patients [Figure 11]. It is technically difficult to apply the LAD over the face and perineum.

\section{LAD designs}

Based on the material that contacts the wound LAD is classified into two groups: 

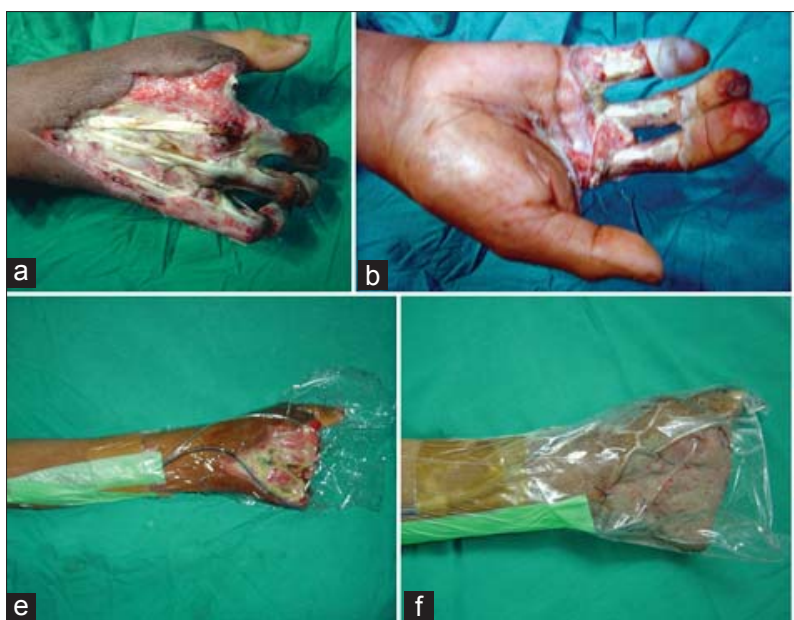
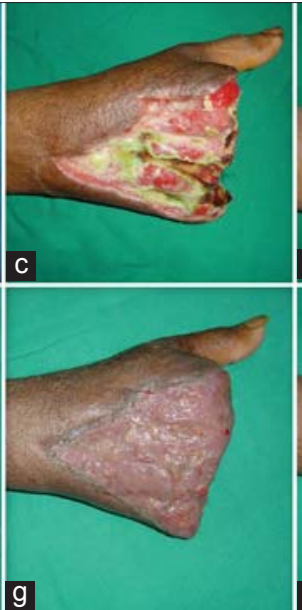

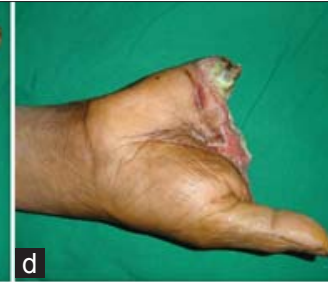

d

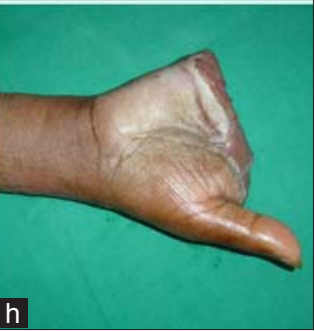

Figure 11: $(a, b)$ Postinfective gangrene fingers of right hand in a known diabetic-index finger amputated outside; $(c, d)$ gangrenous fingers amputated and minimal wound debridement was done; (e,f) wound prepared in 3 weeks under LAD and skin graft done under LAD; $(\mathrm{g}, \mathrm{h})$ Appearance of hand 7 days after grafting

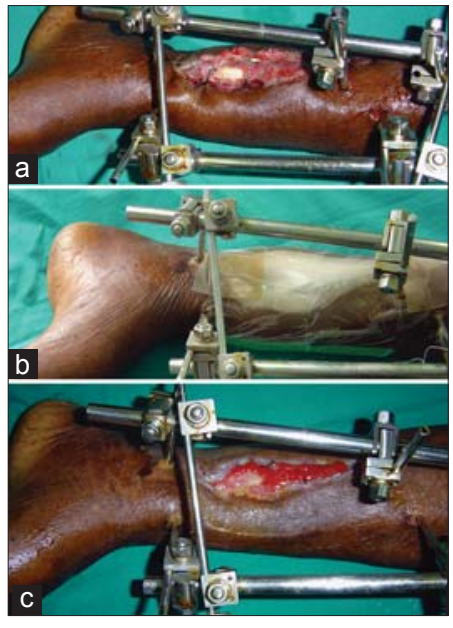

Figure 12: (a) Photograph showing post-traumatic wound with exposed tendon; (b) Wound managed by LAD I; (c) Appearance of the wound after 2 weeks.

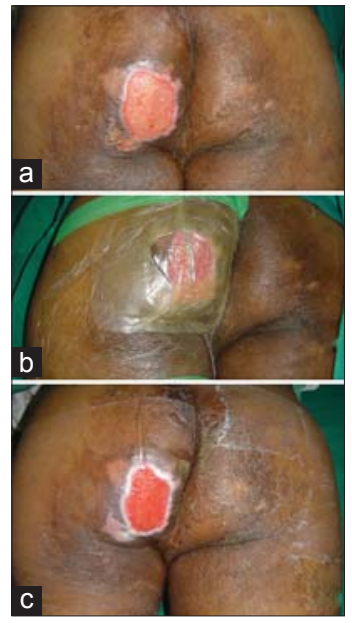

Figure 13: (a) Photograph showing pressure ulcer left buttock; (b) Wound managed by LAD IB; (c) Appearance of the wound after 5 days of LAD IB.

1. LAD design with hydrocolloid material in contact with the wound (LAD I): Some may be skeptical as to whether a hydrocolloid material encountering the wound or negative pressure in LAD I [Figure 12] makes a difference. Liquefied hydrocolloid materials blocking the tube, and poor wound floor visibility for the initial few days until the suction removes any liquefied material, are two additional problems. LAD-I is now replaced by LAD IB.

2. LAD designs with Polythene sheet in contact with the wound (LAD IB and LAD II): To avoid doubts and problems associated with LAD I, in LAD IB [Figure 13] a sterile polythene sheet separates the wound (with tubes placed over it) from the Hydrocolloid material in which a central hole is made to improve visibility. LAD I and LAD IB were used for smaller size wounds (depending on available size of the hydrocolloid material).

\section{LAD II application}

For LAD II either ethylene oxide presealed/ customized sterilized polythene $(0.15-\mathrm{mm}$ thick) $\mathrm{patch} / \mathrm{tube} / \mathrm{bags}$ [Figure 14] of different sizes are used; or based on the size, shape, and wound site, customized bags can be sealed using a semiautomatic sealing machine and sterilized by immersion in $2.45 \% \mathrm{w} / \mathrm{v}$ glutaraldehyde solution for 20 minutes. Although the polythene sheet of LAD is not permeable to water vapour, the moisture is effectively removed intermittently along with secretions by negative suction.

Over a period of time many improvements have been done over earlier design. To avoid any confusion due to earlier publications, in the present review, both earlier design and improvements is being mentioned.

Indian Journal of Plastic Surgery May-August 2012 Vol 45 Issue 2 

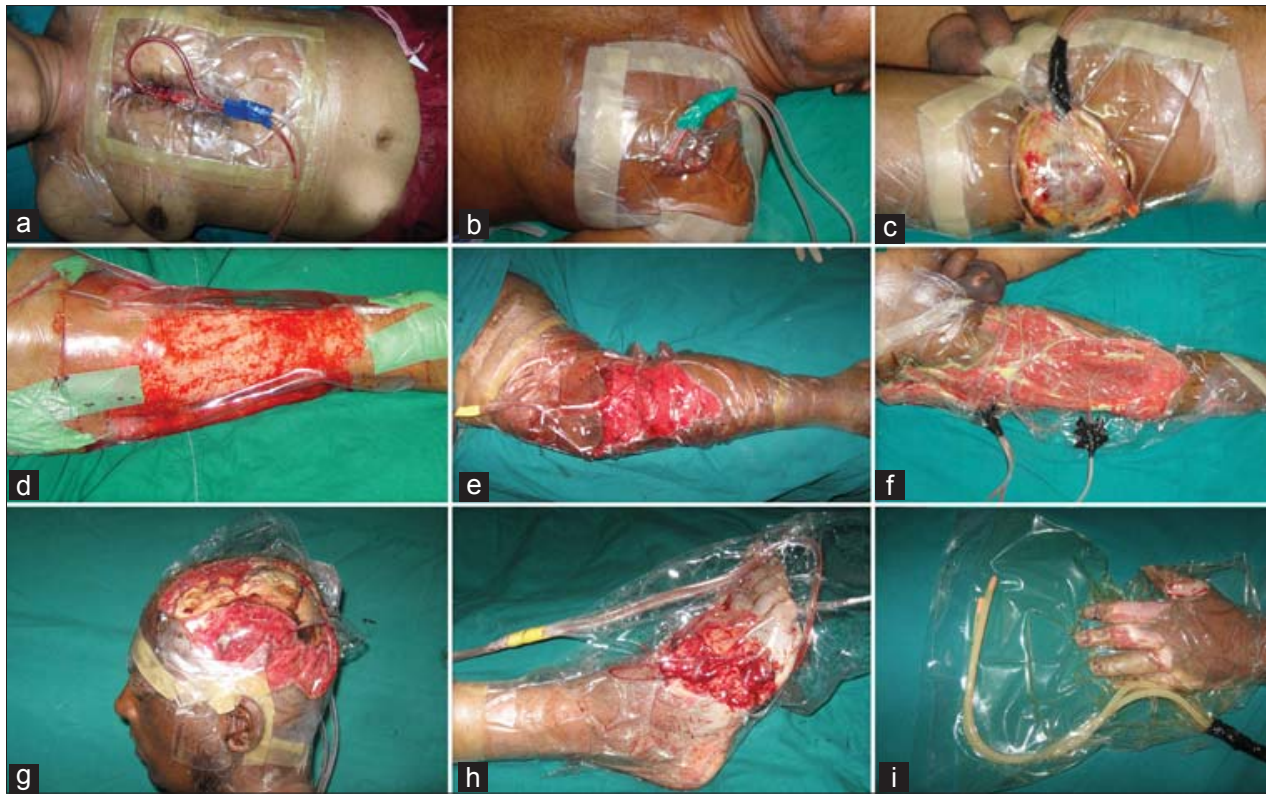

Figure 14: Photographs showing various designs of LAD II; (a-c) Photograph showing LAD patch design for sternotomy wound, exposed pace maker and electric burn wound over thigh; (d-f) Tubular LAD for donor area, leg wound and thigh wound; (g-i) Bag design of LAD for scalp, leg and hand

\section{Earlier design of LAD II}

The LAD tubes come between skin surface and LAD polythene at the site of sealing.

\section{Improved design of LAD II}

With wider exposure to the technique and improved design, it is possible to use various designs of LAD II for all sizes and types of wounds (avoiding use of LAD I and LAD IB). Hence, for convenience of the description term now onwards 'LAD II' will be replaced by 'LAD'. Thinner tubes of earlier design are replaced by $16-18$-Fr feeding tube with extra holes as required. In LAD the polythene cover are used in three basic designs-patch, tubular, and bag design [Figure 14].

\section{IMPROVEMENT TO REDUCE LAD LEAK ${ }^{[20]}$}

In earlier design tubes, that comes out between LAD polythene and skin surface, increase the chance of leak as the slightest side to side movement of the tubes produces gap between sealing material and skin. To reduce the chances of leak, in the improved design of $\mathrm{LAD}$, tubes are brought out of the plastic bag through a specially designed separate port through the plastic, and the site of puncture is sealed with hydrocolloid material and sterilized electrical insulation tape [Figure 1a-b].

The second common site of leak is near the most dependent portion of the seal. The water-soluble hydrocolloid material (used for sealing) in contact with

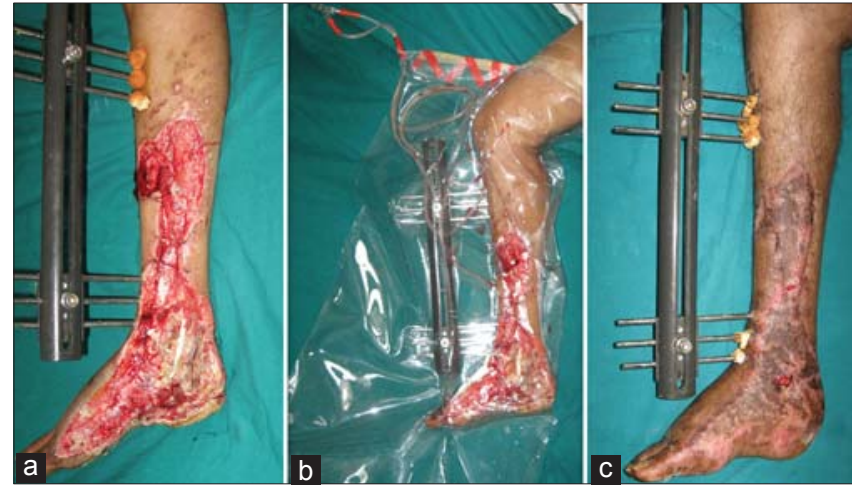

Figure 15: LAD bag to be applied over external fixator is made by thicker polyethylene material to avoid damage by fixator pins (see text for detail);

(a) Post-traumatic raw area with exposed bone, ankle joint and tendons;

(b) Wound managed under LAD; (c) After 6 weeks granulation covered the exposed vital structures and split skin graft was done

wound secretions gets dissolved and produces leak. Also, during daily LAD wash ${ }^{[12]}$ hydrocolloid material is dissolved causing leak in the system. To solve this problem a recess is incorporated the design of polyethylene $L A D$ bag or tube near the hydrocolloid seal [Figure 1b]. While applying the LAD bag is oriented in such a way that the tube port lies at the upper border of the LAD.

\section{MANAGEMENT OF LAD LEAK}

Management of LAD leak is done as per their severity [Table 5].

\section{APPLICATION OF LAD AFTER SPLIT SKIN GRAFTING}



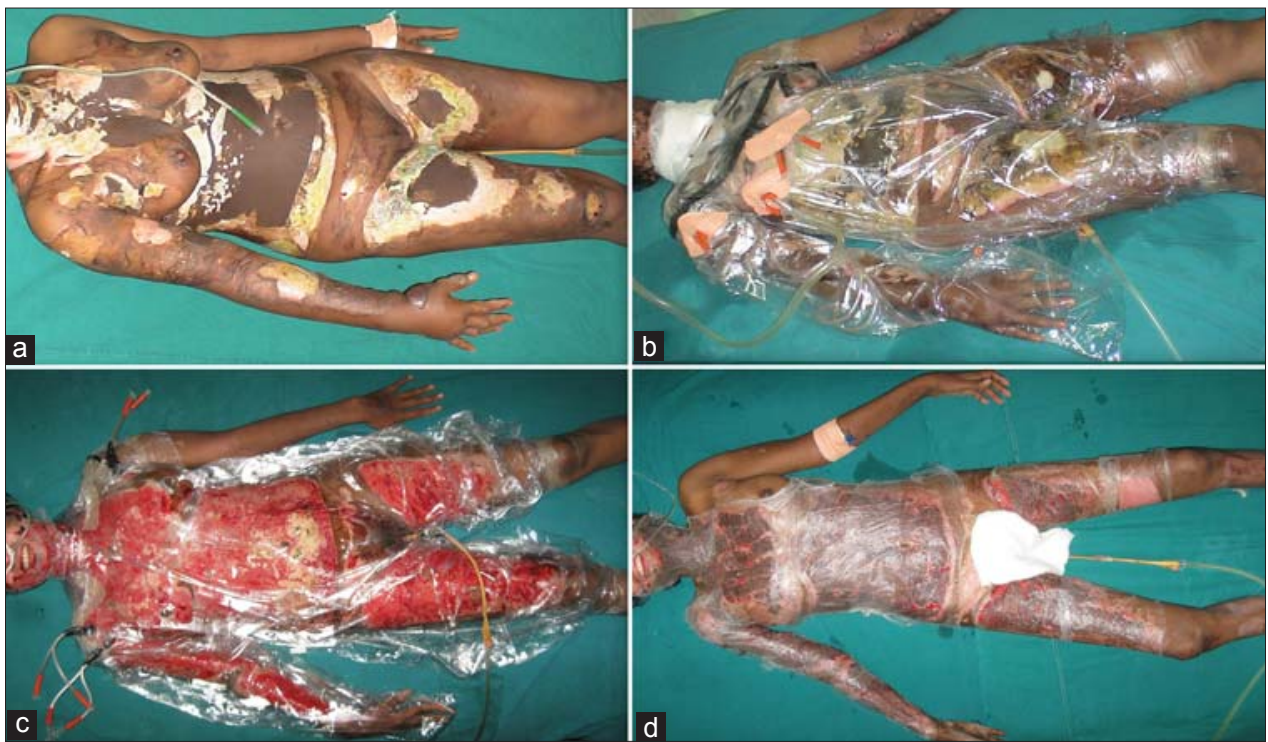

Figure 16: (a) Photograph showing deep thermal burn involving extensive area; $(b, c)$ Wound managed under LAD for 30 days when healthy granulation appeared and split skin grafting was done; (d) Appearance after 10 days of skin grafting
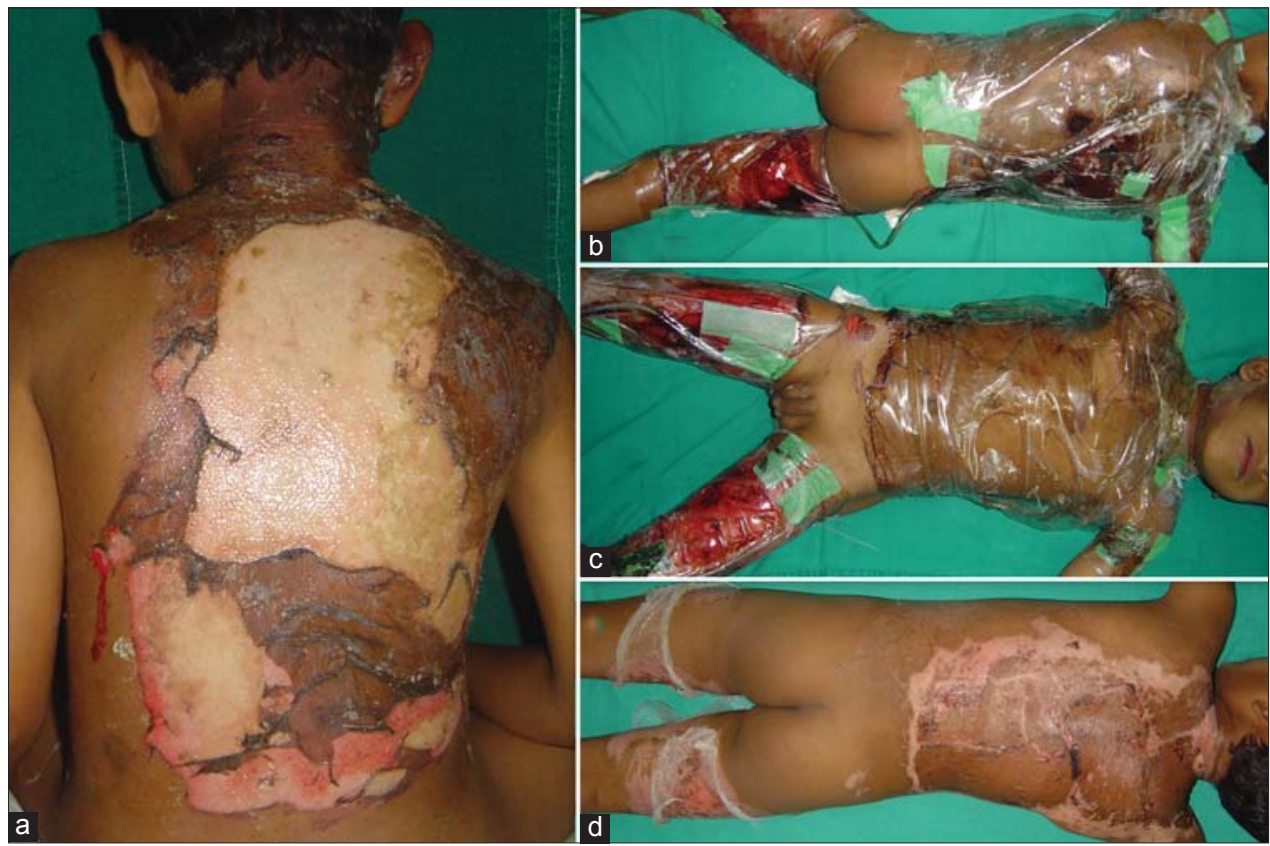

Figure 17: Photograph showing tangential excision and split skin grafting under LAD; (a) Photograph showing deep burn of back; (b,c) Tangential excision and split skin grafting was done and LAD applied over both donor and recipient area for 10 days; (d) Appearance on $18^{\text {th }}$ post-burn day

Split-thickness skin grafts are covered with a nonstick polyolefin mesh that is sutured to skin surrounding the wound to avoid accidental displacement of the graft during suction [Figures $5 c$ and e]. The LAD is removed on $10^{\text {th }}$ postoperative day.

\section{Application of LAD over donor area}

LAD may be applied over donor area in two ways:

1. Two layers of nonstick polyolefin mesh with 16-18 Fr tubes placed between the two layers are used to cover donor areas in all cases, which in turn are covered with an adhesive polyurethane film.

2. In second method tubular LAD is used [Figure 14d]. Nonadherent layer is not required.

Donor area LAD is removed on $6^{\text {th }}$ day and convention donor area dressing is done. Frequency of further dressing change is decided on the condition of the wound.

\section{LAD for wounds with external fixator}

Indian Journal of Plastic Surgery May-August 2012 Vol 45 Issue 2 
Use of thicker polythene material (0.4-mm thick) for LAD bag and covering ends of the pins by soft material tubes reduces chances of damage to LAD by external fixator pins [Figure 15]. The bag is kept loose to avoid excessive pain due to pull on the soft tissue Sealing is done in usual way after applying staples to hold two free edges of the polythene near the mouth of the LAD bag above the skin. Just before applying negative pressure polythene bag is made to hug skin in as much area as possible.

\section{Self-sealing design}

A self-sealing LAD bag design may be made by placing the port through the plastic distally [Figure 1a]. Suction should be applied after applying slight pressure manually at the site of leak or after tying a semiocclusive bandage..$^{[20]}$

\section{Extensive area LAD or whole-body LAD utilizes}

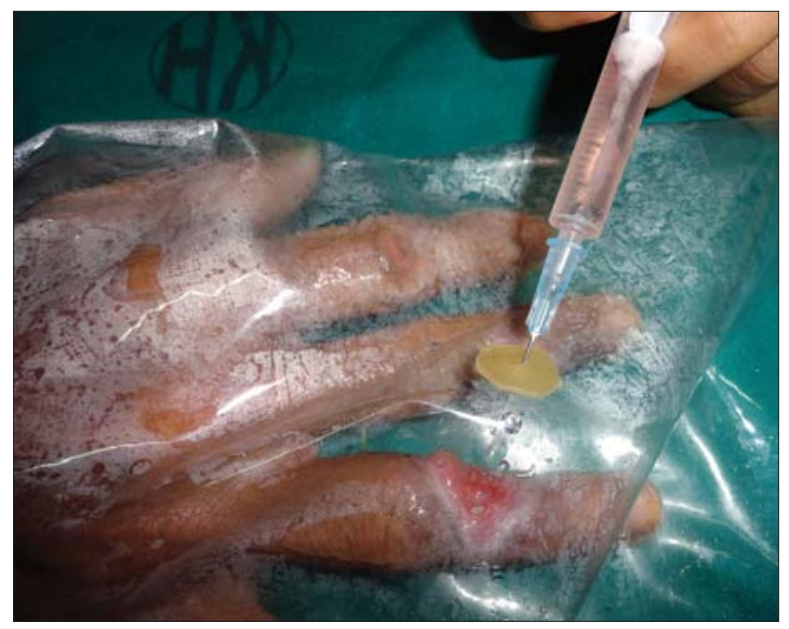

Figure 18: Intra-LAD delivery of drug through a self-sealing port made by the hydrocolloid material

\section{concept of LAD II}

Except for the face and perineum, it is possible to apply LAD all over or any part of the body [Figures 16 and 17]. While applying LAD in difficult areas like perineum, plastic sheet may be stitched to skin leaving natural orifices with adequate space around it.

Alternative to whole body LAD, one can apply upper body LAD up to waist and both lower extremity LAD up to both groins. The remaining area between upper body and lower extremity LADs can be dressed by conventional bandage dressing and changed at desired intervals.

\section{LAD PROCEDURES}

\section{LAD wash}

Control of bad odour and removal of colonized bacteria is achieved by saline wash and / antimicrobial solution of choice through the LAD tubes. Proper positioning avoids liquefaction of hydrocolloid material due to contact with wash fluid and hence any leaks.

\section{Manipulation of intra-LAD environment}

Intra-LAD isolated wound environment provides opportunity to treat MDR infection by manipulating wound environment (anaerobic to aerobic) and using physical agents (e.g., photon energy through fiber optic, ultrasound, and changes in osmosis and $\mathrm{pH}$ ) within the closed space of the LAD.

\section{Intra-LAD drug delivery}

To reduce wastage of costly topical drugs or stem cells or stem cell culture medium for the advance wound care, small

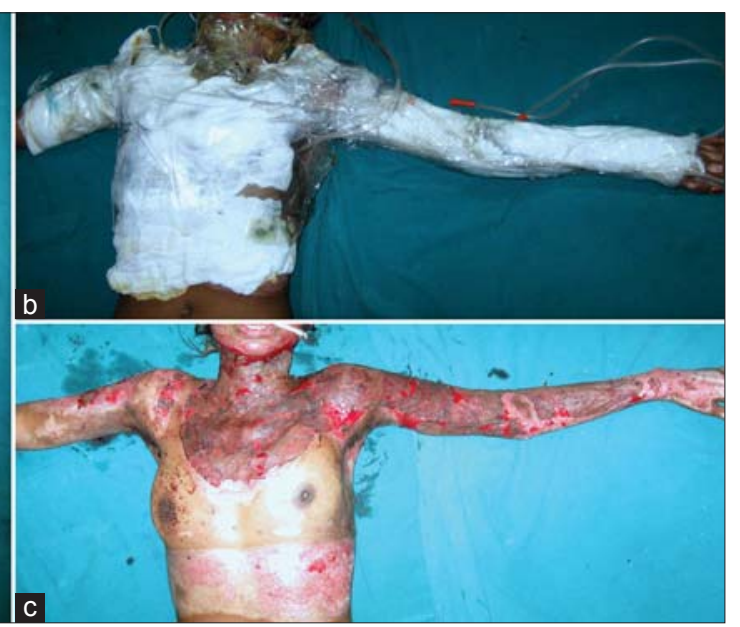

Figure 19: Photograph showing wound management by SAD. (a) Post-burn raw area with $50 \%$ graft take on $15^{\text {th }}$ postoperative day; (b) After split skin grafting, SAD applied; (c) SAD is covered by Gamzee pads and bandage without any sealing 
button of thick hydrocolloids material on polyurethane film is cut and stuck to the convenient point on the LAD polythene cover and drug injected through it in oblique direction (not perpendicular) [Figure 18]. This acts as self-sealing port as the needle track through the adhesive hydrocolloid material closed on application of negative pressure. ${ }^{[20]}$

\section{LAD zipper surgery}

Repeated removal of the LAD may increase the cost and inconvenience, it is possible to incise polythene cover of the LAD in nondependent area, work on the wound through it. The incised area is resealed after slightly overlapping the incised edges. Reopening and resealing at the same site is done for repeat procedures. ${ }^{[20]}$

\section{INTRA-LAD PHYSIOTHERAPY}

When the triad of oedema, immobility, and inflammation coexist, a vicious cycle develops with each feeding off the other, resulting in rapid stiffening of uninjured joints and tendon adhesions. ${ }^{[21]}$ Generally, a favourable situation results if two of the three factors are controlled. Edema is controlled by the intermittent compression produced via the negative pressure combined with early intraLAD mobilization. Early intra-LAD physiotherapy helps minimize stiffness-the most common cause of persistent physical impairment in hand trauma cases.

\section{LAD protocol for trauma: early wound isolation}

Unlike granulating wound, all the open lymphatic channels on the surface exhibit better leech effect. Low negative pressure reduces risk of bleeding from open capillaries. Risk of bleeding is reduced by applying pressure bandage after covering the wound with nonadherent material followed by application of self sealing LAD. After 24-48 hrs, pressure dressing is removed, $\mathrm{LAD}$ is reapplied and sealed.

Advantages of early LAD application in trauma cases: ${ }^{[22]}$

- Early application of LAD application reduces chances of contamination and infection

- Reduced number of debridement

- Reduced wound coverage time

- Reduced total hospital stay

- Simpler reconstruction without significant problems in recipient area

- Better functional result

- Cost effectiveness.

\section{Auto-debridement in LAD}

It is time consuming and during the period of auto- debridement, unfavourable wound environment producing SIRS and infection is controlled by LAD satisfactorily. Auto-debridement occurs in two ways:

1. Autolytic debridement ${ }^{[23]}$ occurs by phagocytosis and body enzymes in moist environment. Viable cells proliferate and dead cells are shed (ultraconservative debridement).

2. Mechanical debridement occur during suction and LAD wash.

After about 7-10 days of post-LAD, surgical removal of dead tissue becomes easy with minimal blood loss.

\section{ADVANTAGES}

1. All the advantages moist wound healing is retained. Edge of LAD over moist healing are:

- The pus like gel (usually a source of concern to the patients in hydrocolloid dressings) produced due to dissolved hydrocolloid material is not a problem in LAD.

- $\quad$ LAD wash reduces foul smell of moist dressing.

- Weak and limited absorbent capacity of moist dressing material is replaced by negative pressure that never gets saturated.

- Wound environment not suitable for anaerobic growth.

2. All the advantages negative pressure dressing is retained. Intermittent negative pressure makes LAD more acceptable and economical.

3. Additional advantages:

- Wound remains visible through polythene.

- Epithelialisation is better than other negative pressure dressings where sponge is used.

- Wound environment manipulation is possible.

- Consistently better graft take under LAD appeared to be due to control of infection and intermittent compressions of graft between polythene sheet and recipient area. High levels of vascular endothelial growth factor (VEGF)-associated with negative pressure dressing may also be responsible for better graft take. ${ }^{[24,25]}$

- Wound bed preparation under LAD is faster than conventional dressing. Overall graft take under LAD was $99.87 \% .^{[12,22]}$ 
- In cases of compound comminuted fractures problems due to movements associated with frequent change of dressing is avoided.

- Intermittent negative pressure with the LAD may reduce the need for DVT prophylaxis ${ }^{[26]}$ in immobilized patients with lower extremity wounds.

\section{DISADVANTAGES}

- Undesirable effects of negative pressure

Bleeding and ulceration may be avoided by low negative pressure. Bleeding may be reduced by placing tube away from the wound [Figure 1] and, ulceration by designing larger size LAD bag and allowing some air to enter in bag during rest period. ${ }^{[20]}$ To avoid ulcerations in patch LAD, the closed end of the tube nay be made less rigid by cutting the end of feeding tube and then making multiple $0.5-\mathrm{cm}$ longitudinal slits from the cut end.

High negative pressure may produce intolerable pain.

Ineffective negative pressure may invite disadvantages of moist wound healing.

- Bad odour is reduced by daily saline LAD wash. In operating room before changing LAD, multiple punctures are made in the polythene sheet and tubes are connected to central suction for few minutes.

\section{SUCTION-ASSISTED DRESSING}

Moist wound dressings retain moisture, heat, body fluids, and medication. It maintains the moist and warm wound environment suitable for growth of the granulation tissue, controls wound infection, increases rate of epithelialisation and reduces pain.

Earliest notations of occlusive wound therapy is contained in the Smith Papyrus of 1615 B.C., which asserted that closed wounds heal more quickly than open wounds and described creating dressings out of linen strips that were covered with a gum-like substance. However, Hippocrates contended that physicians should not endeavor to close chronic wounds. ${ }^{[27]}$

In India moist wound healing has gained considerable popularity in the last few years and a variety of products is available in the market. Moist wound dressings are ideal for dressing dry wounds or wounds with low levels of exudates. But, moist wound dressings have several disadvantages. Fully occlusive dressings like hydrocolloids can occasionally (if liquefied hydrocolloid material is left in contact for longer duration) cause over hydration of wound and maceration of the intact skin surrounding the wound. Moist environment may lead to offensive-smelling exudates, bacterial proliferation and wound infection, specifically anaerobes..$^{[3-7]}$

Majority of the moist wound dressings absorb exudates, produces an absorption gradient that removes the toxic components of the wound exudates. ${ }^{[28]}$ Hence, changing the moist wound dressing at frequent interval (depending on its absorbent capacity) will reduce the problems of over hydration, maceration, odour and infection. Frequent change of moist dressing is relatively expensive.

Negative pressure dressing removes wound exudates and toxins and hence, like moist dressing is effective method for wound management. Capacity of negative pressure to remove fluid is unlimited and hence, can be used to treat wound with any amount of soakage. Similar to occlusive moist wound dressing, occasionally (especially if not changed frequently) conventional closed (semiocclusive) bandage can cause over hydration of wound and maceration of the intact skin surrounding the wound. To reduce this problem in closed bandage dressing, author has devised a suction assisted dressing (SAD) where conventional closed bandage technique is combined with low pressure intermittent negative pressure. Technique is simple, cost effective and avoids some of the problems associated with over hydration and moist environment. In SAD, the initial dressing is done as in any semiocclusive bandage dressing. Application of a layer of non-adherent material (if required) is followed by one or two layers of gauzes. Over the gauzes two tubes (feeding tubes 12-18-Fr size with multiple smaller holes) fixed to non porous plastic sheet is placed and then cotton pad and bandaging is done. The difference from usual negative pressure dressing is that no sealing is done and tubes are placed over the absorbent gauze layer not over the wound. SAD effectively combines the effect of weak negative pressure and wound environment is relatively less moist due to flow of air during suction period. Thus, SAD increases the effectiveness of absorbent gauze layer by increased capillary action due to flow of air on the surface of the gauze and removal of the moisture from the superficial surface of the absorbent gauze. Author has found SAD very effective in cases 
where there are mild moist environment is beneficial for healing as in the cases of split skin grafting and superficial skin wounds (e.g., superficial burn, split skin graft donor area, friction wounds). The result of SAD in a representative case is shown in Figure 19. SAD appears to be a better and cost effective replacement of moist dressing for extensive suitable wounds. Author has kept SAD in place maximum for 7 days.

\section{REFERENCES}

1. Orgill DP, Bayer LR. Update on negative-pressure wound therapy. Plast Reconstr Surg 2011;127 Suppl 1:105S-115S.

2. Gupta S, Bates-Jensen B, Gabriel A, Holloway A, Niezgoda J, Weir, D. Differentiating Negative Pressure Wound Therapy Devices: An Illustrative case series. Wounds 2007;19:1-9.

3. Winter GD. Epidermal regeneration studied in the domestic pig. In: Maibach HI, Rovee DT, editors. Epidermal Wound Healing: Chicago, III Year Book Medical Publishers; 1972. p. 71-112.

4. Bennett RG. The debatable benefit of occlusive dressings for wounds. J Dermatol Surg Oncol 1982;8:166-7.

5. Geronemus RG, Robins P. The effect of two new dressings on epidermal wound healing. J Dermatol Surg Oncol 1982;8:850-2.

6. Ryan TJ. Current management of leg ulcers. Drugs 1985; 30:461-8.

7. Gilchrist B, Reed C. The bacteriology of chronic venous ulcers treated with occlusive hydrocolloid dressings. $\mathrm{Br} \mathrm{J}$ Dermatol 1989;121:337-44.

8. Aly R, Shirley C, Cunico B, Maibach HI. Effect of prolonged occlusion on the microbial flora, $\mathrm{pH}$, carbon dioxide and transepidermal water loss on human skin. J Invest Dermatol 1978;71:378-81.

9. Marples RR, Kligman AM. Growth of bacteria under adhesive tapes. Arch Dermatol 1969;99:107-10.

10. Eriksson E. Comparative study of hydrocolloid dressing and double layer bandage in treatment of venous stasis ulceration. In: Ryan TJ, editor. An Environment for Healing: The Role of Occlusion: London, Royal Society of Medicine; 1985. p. 45-9.

11. Finegold SM. Pathogenic anaerobes. Arch Intern Med 1982;142:1988-92.

12. Kumar P. Limited Access Dressing. Wounds 2008;20:49-59.

13. Kumar P. Limited Access Dressing (Review Article). Journal SWCR 2011;4:55-56.
14. Kannon GA, Garrett AB. Moist wound healing with occlusive dressings. A clinical review. Dermatol Surg 1995;21:583-90.

15. Kumar P. Suction Assisted Dressing (SAD). Journal SWCR 2011;4:74-6.

16. Guyton AC, Hall JE. The microcirculation and the lymphatic system: capillary fluid exchange. $9^{\text {th }}$ editon. Interstitial fluid and lymph flow. Textbook of Medical Physiology. S.B. Saunders Company: USA; 1998. p. 183-97.

17. Simmons EM, Himmelfarb J, Sezer MT, Chertow GM, Mehta RL, Paganini EP, et al. Plasma cytokine levels predict mortality in patients with acute renal failure. Kidney Int 2004;65:1357-65.

18. Kumar P. Limited Access Dressing and Maggots. WOUNDS 2009;21:150-2

19. Kumar P, Sethi N, Friji MT, Poornima S. Wound healing and skin grafting in ehlers-danlos syndrome. Plast Reconstr Surg 2010;126:214 e-215 e.

20. Kumar P. Improved LAD II design (Letter). Journal SWCR 2011;4:77-9

21. Beasley RW. The stiffened hand. In: Evarts CM(editors). Surgery of the Musculoskeletal System. Vol 1. Churchill Livingstone: New York, NY; 1983. p. 693-706.

22. Kumar $\mathrm{P}$, Sharma $\mathrm{A}$. The limited access dressing for damage control in trauma patients. Wounds. 2010;22:188-92.

23. Sieggreen MY, Maklebust J. Debridement: choices and challenges. Adv Wound Care 1997;10:32-7..

24. Téot L, Otman S, Hussenet P, Moles J. Expression of angiogenic factors in chronic wounds treated with negative pressure therapy. Presented at: the $10^{\text {th }}$ Annual Meeting of the European Tissue Repair Society; May 2000; Brussels, Belgium.

25. Giovannini UM, DemariaRG, Teot $L$. Interest of negative pressure therapy in the treatment of postoperative sepsis in cardiovascular surgery. Wounds 2001;13:82-7.

26. Urbankova J, Quiroz R, Kucher N, Goldhaber SZ. Intermittent pneumatic compression and deep vein thrombosis prevention. A meta-analysis in postoperative patients. Thromb Haemost 2005;94:1181-5

27. Eaglstein $\mathbf{W H}$. Moist wound healing with occlusive dressings: a clinical focus. Dermatol Surg 2001;27:175-81.

28. Turner TD. Semi-occlusive and occlusive dressings. In: Ryan TJ (editor). An Environment for Healing: The Role of Occlusion. London: Royal Society of Medicine; 1985. p. 5-14.

How to cite this article: Kumar P. Exploiting potency of negative pressure in wound dressing using limited access dressing and suction-assisted dressing. Indian J Plast Surg 2012;45:302-15.

Source of Support: Nil, Conflict of Interest: None declared. 